results eliminates the principal source of error which has given rise to problems encountered with the Corning kit, and the manufacturers have now incorporated this change into their recommended protocol. ${ }^{4}$ Nevertheless other, albeit relatively minor, TBG-dependent effects (for example, the "non-specific" binding of radioactive T4 to the solid-supported antibody used in this kit) may influence free T4 determinations made on the basis of the recommended Corning assay procedure, and thereby distort free $\mathrm{T} 4$ values in subjects in whom thyroxine-binding protein concentrations are significantly altered. The physiological significance of small changes observed in pregnant subjects in serum free T4 (as measured using the Corning technique) may in consequence be questionable, although the use of this kit in a diagnostic role may not be significantly compromised by any minor residual sources of error that it may contain.

Meanwhile a reduction in free $\mathrm{T} 4$ concentration during pregnancy has'also been reported by a number of other workers (for example, Avruskin et $a l^{5}$ and Arango et $a l^{6}$ ) using a variety of conventional free $\mathrm{T} 4$ assay techniques (albeit the magnitude of the effect has been less than that reported by Boss et al). Many of these techniques have likewise proved to be methodologically suspect, yielding apparent free $\mathrm{T} 4$ values significantly higher than those observed with modern "direct" methods (see, for example, Ekins ${ }^{7}$ ). Were the observation of a reduced free thyroid hormone concentration in pregnancy to be confirmed, however, speculation must arise regarding the physiological role of the free hormone moiety and the nature of mechanisms governing thyroid hormone transport and control.

In attempting to establish the validity of the reported changes in pregnancy, we have used a new "direct" method for free T4 measurement de veloped in this laboratory. In brief, the method involves the incubation, at $37 \mathrm{C}$ for one hour, of serum with $\mathrm{T} 4$ antiserum linked to a particulate solid support (Sephadex) followed by separation of the antibody from the serum; subsequently the amount of $\mathrm{T} 4$ bound to antibody is estimated by "back titration" with ${ }^{125}$ I-labelled T4. Serum standards for the system have been calibrated by an equilibrium dialysis technique relying on direct radioimmunoassay of T4 in the dialysate. ${ }^{\text {. }}$ (This method represents an entirely novel approach to free hormone measurement, the theoretical and methodological basis of which will be presented in detail elsewhere.)

Serum samples were collected from normal women attending a gynaccological clinic for contraceptive advice (none were on oral contracep tives) and also from pregnant patients attending the antenatal clinic. To minimise any possible methodological bias normal and pregnancy sera were placed as alternate samples within each assay batch. The normal samples yielded a mean free $\Gamma 4$ concentration of $15.12 \mathrm{pmol} / 1(1.17 \mathrm{ng} / 100 \mathrm{ml})$ (n $100, \mathrm{SE}$ of mean $0.32(0.02)$ ) with a range of $9 \cdot 8-22.4 \mathrm{pmol} / 1(0.76-1.74 \mathrm{ng} / 100 \mathrm{ml})$. For the pregnancy samples the mean concentration was reduced to $13.6 \mathrm{pmol} / \mathrm{l}(1.06 \mathrm{ng} / 100 \mathrm{ml})$ (n 123 SE of mean $0.26(0.02) ; t \quad 3.68)$. The results of the 101 patients whose stage of pregnancy was known are shown in the figure. The free $\mathrm{T} 4$ concentration appeared lower in the second half of pregnancy, with a mean value of $12.2 \mathrm{pmol} / 1$ $(0.95 \mathrm{ng} / 100 \mathrm{ml})(\mathrm{n}-45$, SE of mean $0.33(0.02)$ : in the first half of pregnancy the results were near normal (mean concentration $14.4 \mathrm{pmol} / 1(1 \cdot 12 \mathrm{ng}$ $100 \mathrm{ml})$ (n 56, SE of mean $0 \cdot 4(0.03)$ ).

Thus our results, using a different analytical method, give some support to the original data of Boss et al, notwithstanding the errors introduced into their observations by their use of an invalid calculation procedure. Recalculation of their FT4 results (see their letter on $\mathrm{p} \mathrm{550)}$ ) alters the nature of the agreement between their data and ours (in as much as we do not confirm a rise in FT4 in the first trimester); the latter observation may reflect the minor residual errors that are suspected to remain in the Corning assay procedure.

Apart from the fundamental questions these

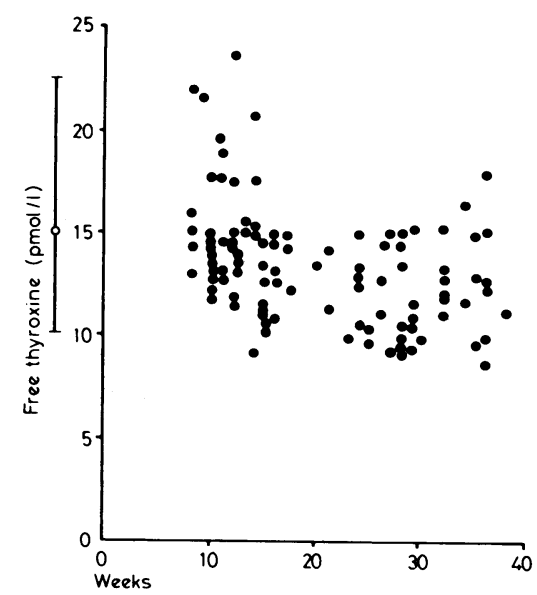

Relationship between the serum free $\mathrm{T} 4$ concentration and the stage of pregnancy in 101 subjects; the bar indicates the mean and normal range in nonpregnant controls.

Conversion: SI to traditional units-T $4: 1 \mathrm{pmol} / 1$ $\approx 0.08 \mathrm{ng} / 100 \mathrm{ml}$.

observations, taken together, must raise relating to the nature of the pituitary homoeostatic mechanism governing circulating thyroid hormone levels and thyroid hormone delivery to peripheral cells, they are clearly relevant to the diagnosis and management of thyroid disease in pregnancy.

ANTONY KURTZ

KEVIN DWYER

ROGER EKINS

Subdepartment of Molecular

Biophysics,

Department of Nuclear Medicine,

Middlesex Hospital Medical School,

W1N 8AA

' Boss, $\mathrm{M}$, Djahanbakhch, $\mathrm{O}$, and Kingstone, D, British Medical fournal, 1978, 2, 1496

Hale, T I, Lancet, 1979, 1, 980

Ekins, R, Lancet, 1979, 1, 1190. Fullarton, J, and Lidgard, G P, Lancet, 1979, 2, 51.

Sclences, 1976, 271, 309 .
Arango, G, et al, Mayo Clinic Proceedings, 1968, 43,

503 .
Ekins, R , in Proceedings of the International Symposium on Free Thyroid Hormones, Venice, 1978 sium on Free Thyrold Hor

- Ekins, R P, and Ellis, S M, in Proceedings of the Seventh International Thyroid Conference, Boston, Massachusetts, 1975.

\section{General practitioners' advice against smoking}

SIR,-The many and serious health hazards of cigarette smoking are undisputed; almost daily the evidence grows. Yet, despite brave talk, little action follows and doctors are as culpable as any.

The findings of $\mathrm{Dr} \mathrm{M}$ A $\mathrm{H}$ Russell and others (28 July, p 231) therefore have great significance. Their conclusion that GPs, collectively, could produce half a million exsmokers a year should be an irresistible challenge-the opportunity to make a major contribution to the health of our patients and reduce the 50000 excess deaths a year attributable to cigarette smoking. Even the "six-minute consultation" is surely no excuse for failure to give the simple, firm, antismoking advice, anti-smoking leaflet, and threat of future inquiry which their study demonstrates to be effective. The feelings of impotence which at present inhibit action must be dispelled.

One minor anxiety, however, relates to the presumed low deception rate reported by Dr Russell and his colleagues; stronger evidence for this would have been reassuring especially in view of the findings of Sillet et al. ${ }^{1}$ Furthermore, with the substantial influence of social class on cigarette smoking and especially on smoking cessation, ${ }^{2}$ the absence of social class information is particularly regrettable.

These comments apart, the message seems clear. Instead of awaiting government antismoking measures, we should ourselves accept the challenge and let no smoker leave the consultation unsolicited.

GODFREY FOWLER Department of Social and Community Medicine, Oxford OX1 3QN ' Sillet, R W, et al, British Medical fournal 1978, 2,
1185. .
' Capell, P, Health Trends 1978, 10, 49 .

\section{Comparison of buprenorphine and diamorphine in suspected myocardial infarction}

SIR,-I read with interest the article by Dr M J Hayes and others (4 August, p 300) comparing buprenorphine and diamorphine after myocardial infarction. They state that no major side effects were experienced with either drug, but do not mention respiratory depression specifically. Presumably this was not a problem, but it may well be that none of the 95 patients to whom intravenous buprenorphine was administered had severe airways disease. Anyone treating myocardial infarcts experiences the occasional patient who is unduly sensitive to diamorphine's respiratory side effects, and naloxone has proved itself as a life-saving drug in this respect. The makers claim that buprenorphine does not depress respiration dangerously, but it certainly can do so postoperatively when used in combination with other drugs. Unfortunately naloxone does not cause quick reversal of buprenorphine-induced respiratory depression.

Sublingual buprenorphine gave as effective analgesia as intravenous, though it was slower in onset. This is an important point for home coronary care, as a frequent reason for failure of treatment at home is recurrence of pain not responding to oral analgesics. If patients were given an intravenous dose of buprenorphine or diamorphine, and told to take sublingual buprenorphine six hourly for 24 hours, this reason for hospital admission might be avoided more often.

H C R SIMPSON

Department of Regius

Professor of Medicine,

John Radcliffe Hospital,
Oxford OX3 9DU

\section{Interstitial fibrosis in a patient treated} with 5-fluorouracil and mitomycin $C$

SIR, - We reported a case of interstitial lung disease in a patient treated with 5-fluorouracil and mitomycin C (26 August 1978, p 602). The results of the investigations reported in the paper were consistent with, though not diagnostic of, fibrosing alveolitis. The patient has now died.

At necropsy the patient was severely cachectic and jaundiced. The cardiovascular system was normal and there was no residual neoplasm in the gastrointestinal system. The liver $(2120 \mathrm{~g})$ was enlarged and contained numerous tumour deposits, and the lymph nodes at the porta hepatis 